\title{
Carcinoma Breast with Ectopic Intrathoracic Thyroid Tissue: A Rare Presentation
}

\begin{abstract}
Ectopic intrathoracic thyroid is very rare and represents only about $1 \%$ of mediastinal tumors. Mediastinal mass in a patient with an otherwise early-stage breast cancer needs evaluation. If the mass is a metastatic lymph node, it changes the entire treatment plan and prognosis. Here, we describe a case of a 57-year-old female presenting with a lump in the right breast of 6 months. Tru-cut biopsy of the lump showed infiltrating duct carcinoma, Grade III, triple-negative. Staging workup showed a mediastinal mass in addition to the right breast mass and ipsilateral axillary lymphadenopathy. Biopsy from the mediastinal mass was suggestive of an intrathoracic thyroid.
\end{abstract}

Keywords: Carcinoma breast, ectopic, intrathoracic thyroid

\section{Introduction}

Ectopic thyroid is defined as thyroid tissue not located anterolateral to the second and fourth tracheal cartilages. ${ }^{[1]}$ About $90 \%$ of all ectopic thyroid tissues (ETTs) are found along the path of initial embryologic descent of the thyroid gland from the floor of the primitive foregut to its normal pretracheal position. Ten percent have been reported in other anatomical locations, including the mediastinum, trachea, and the heart. ${ }^{[2]}$ ETT is a rare finding in the mediastinum and constitutes only $1 \%$ of tumors in this location. ${ }^{[3]}$ We present a case of a 57-year-old female presenting with locally advanced breast cancer and a mediastinal ectopic thyroid.

\section{Case Report}

A 57-year-old postmenopausal multiparous female with a history of tuberculous lymphadenitis at 32 years of age, which was treated with a full course of antituberculous treatment, now presented with a lump in the right breast of 6 months. She had no family history of any cancer or thyroid disorder. Fine-needle aspiration cytology from the lump showed ductal carcinoma. Examination revealed a $6 \mathrm{~cm} \times 2 \mathrm{~cm}$ hard lump in the upper outer quadrant of the right breast with a movable ipsilateral

This is an open access journal, and articles are distributed under the terms of the Creative Commons Attribution-NonCommercial-ShareAlike 4.0 License, which allows others to remix, tweak, and build upon the work non-commercially, as long as appropriate credit is given and the new creations are licensed under the identical terms.

For reprints contact: WKHLRPMedknow_reprints@wolterskluwer.com
Level 1 lymph node of size $2 \mathrm{~cm} \times 1 \mathrm{~cm}$. General examination including a neck examination was within the normal limits. Digital mammogram showed a normal left breast and BIRDS $\mathrm{V}$ lesion of the right breast. Tru-cut biopsy of the lump showed infiltrating duct carcinoma, Grade III and triple-negative. Her hemogram, serum electrolytes, renal and liver functions were normal. Bone scan did not show any evidence of skeletal metastasis. Her chest X-ray showed mediastinal widening. Hence, a computerized tomography scan of the thorax was done, which revealed the enlarged paratracheal nodal mass of size $5.7 \mathrm{~cm} \times 4.4 \mathrm{~cm} \times 2.8 \mathrm{~cm}$ in addition to the right breast mass and ipsilateral axillary lymphadenopathy [Figure 1]. Due to the disproportionately large mediastinal lymphadenopathy, in addition to metastasis, possibility of tuberculosis was also considered as the cause for the mediastinal node.

Video-assisted thoracoscopic surgery and frozen section from the mediastinal mass was done which showed normal thyroid parenchyma [Figure 2]. The mass was completely resected. Histopathology examination showed thyroid parenchyma with no significant pathology. Therefore, it was concluded that the mediastinal mass was an intrathoracic thyroid. Her thyroid function test was normal with TSH-0.9 mU/L, T3-105 ng/100 ml, and

How to cite this article: Joseph R, Anoop TM, Unnikrishnan P. Carcinoma breast with ectopic intrathoracic thyroid tissue: A rare presentation. Indian J Med Paediatr Oncol 2020;41:758-60.

\section{Rona Joseph, TM Anoop, P Unnikrishnan}

Department of Medical Oncology, Regional Cancer Centre, Thiruvananthapuram, Kerala, India

Submitted: 14-May-2019 Revised: 17-Sep-2019

Accepted: 06-Oct-2019 Published: 29-Oct-2020

Address for correspondence: Dr. Rona Joseph, Department of Medical Oncology, Regional Cancer Centre, Thiruvananthapuram, Kerala, India.

E-mail:ronsjsph@gmail.com

Access this article online

Website: www.ijmpo.org

DOI: 10.4103/ijmpo.ijmpo_116_19 Quick Response Code:
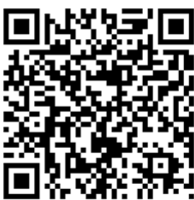


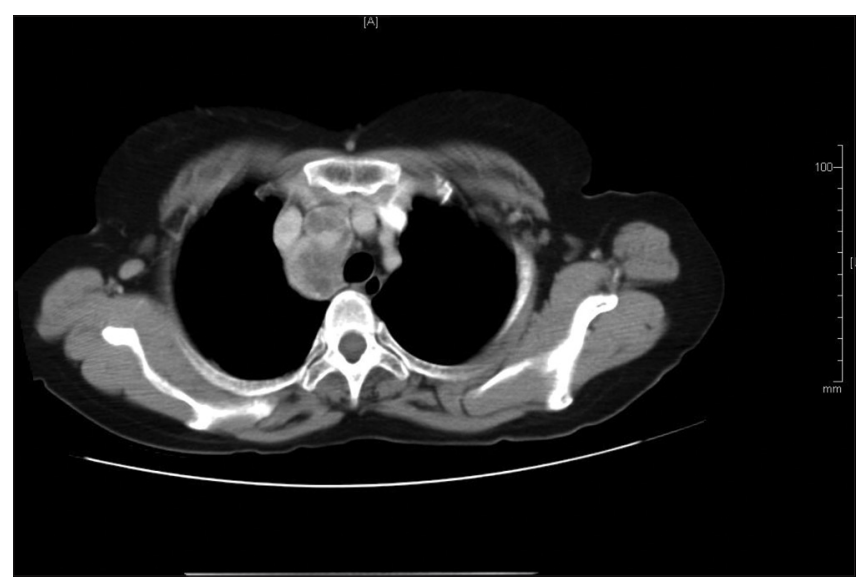

Figure 1: Computed tomography thorax showing enlarged paratracheal nodal mass

T4-7.5 $\mu \mathrm{g} / \mathrm{dL}$. Thyroid scan was not taken. The clinical stage of the disease was T3N1. She received neoadjuvant chemotherapy with three cycles of 5 fluorouracil, epirubicin, and cyclophosphamide followed by three cycles of docetaxel. Following that, she underwent modified radical mastectomy, and the specimen showed ypT1N0 disease. Following this, she received radiation therapy. At present, she is under follow-up.

\section{Discussion}

The thyroid gland originates as a median endodermal thickening on the floor of the primitive hypopharynx about 24 days after fertilization. The primitive gland then descends toward its natural location immediately anterior to the trachea. The developing thyroid gland remains connected to the tongue using a narrow tube, known as the thyroglossal duct. The thyroglossal duct usually involutes at the $6^{\text {th }}$ or $8^{\text {th }}$ week. ${ }^{[1]}$

Ectopic thyroid is an embryological aberration defined as "thyroid tissue not located anterolateral to the second and fourth tracheal cartilages." The prevalence of ETT varies between $7 \%$ and $10 \%$ according to autopsy studies. ${ }^{[4]}$ Ectopic thyroid may develop at various sites from the base of the tongue to any site of the thyroglossal duct due to stoppage of thyroid descent. ${ }^{[1]}$ The cervical midline is the location in $90 \%$ of the cases. ${ }^{[2]}$ Less than $1 \%$ of all ETT occurs in the mediastinum. ${ }^{[4]}$ Heterotopic thyroid in the mediastinum, pericardium, and heart has probably grown from rudiments of developing thyroid dragged into the chest during the descent of the heart and great vessels with the development of the embryonic neck and the unfolding of the embryo. ${ }^{[5]}$

Intrathoracic thyroid may be completely asymptomatic, being found incidentally in a chest radiogram performed for other reasons. ${ }^{[3]}$ The symptoms, when produced, are usually related to compression of upper aerodigestive tracts and superior vena cava. Common symptoms are neck mass, shortness of breath, hoarseness of voice, dysphagia, and

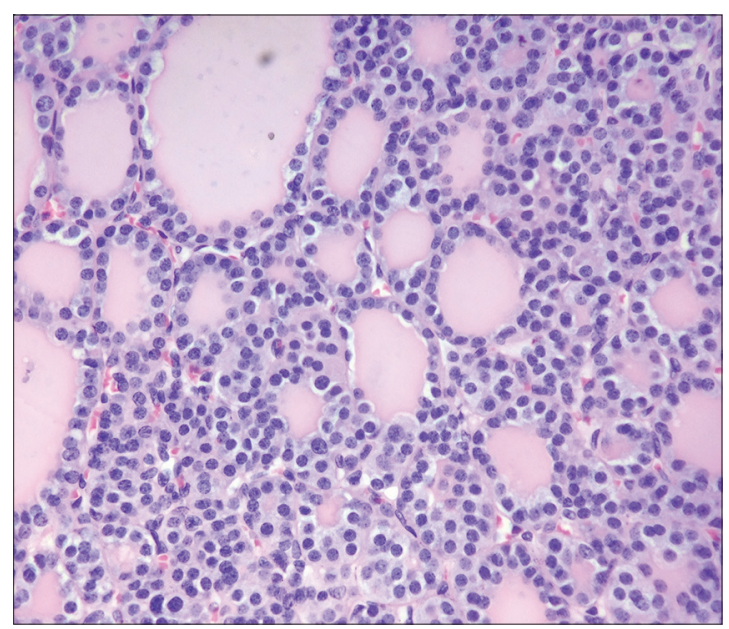

Figure 2: Biopsy from the mediastinal mass showing normal thyroid parenchyma ( $\mathrm{H}$ and $\mathrm{E}, \times \mathbf{4 0})$

stridor/wheezing. ${ }^{[6]}$ The diagnostic procedures currently in use for the evaluation of intrathoracic goiter include chest radiography, ${ }^{[7]}$ computed tomography, ${ }^{[8]}$ radionuclide scintigraphy, angiography, and mediastinoscopic biopsy. I-131 scintigraphy can be considered as a diagnostic test only when ETT has to be suspected. Scintigraphy is not always diagnostic because the uptake of I-131 is not always observed in ETT. Patients are usually euthyroid. ${ }^{[9]}$

Very rarely malignant transformation in ETT can occur. ${ }^{[10]}$ Due to the risks of progressive enlargement, malignant transformation, hemorrhage within the mass, causing respiratory failure and compression of neighboring vital mediastinal organs; these masses should be surgically resected.

Although rare, the possibility of ETT should be considered while evaluating a mediastinal mass. Some of the important differential diagnoses of anterior mediastinal mass include lymphomas, dermoid cysts, and thymic tumors. As in our patient, who has a diagnosis of carcinoma breast, which is otherwise an early-stage lesion, it is extremely important to differentiate it from a metastatic mediastinal lymph node enlargement. Only $2 \%$ of patients with breast cancer show mediastinal lymph node metastases. ${ }^{[11]}$ No significant association was found between ectopic thyroid and carcinoma of the breast, after an extensive literature review.

\section{Financial support and sponsorship}

Nil.

\section{Conflicts of interest}

There are no conflicts of interest.

\section{References}

1. Adelchi C, Mara P, Melissa L, De Stefano A, Cesare M. Ectopic thyroid tissue in the head and neck: A case series. BMC Res Notes 2014;7:790. 
2. Babazade F, Mortazavi H, Jalalian H, Shahvali E. Thyroid tissue as a submandibular mass: A case report. J Oral Sci 2009;51:655-7.

3. Sakorafas GH, Vlachos A, Tolumis G, Kassaras GA, Anagnostopoulos GK, Gorgogiannis D. Ectopic intrathoracic thyroid: Case report. Mt Sinai J Med 2004;71:131-3.

4. Gamblin TC, Jennings GR, Christie DB $3^{\text {rd }}$, Thompson WM Jr., Dalton ML. Ectopic thyroid. Ann Thorac Surg 2003;75:1952-3.

5. Le Roux BT. Heterotopic mediastinal thyroid. Thorax 1961;16:192-6.

6. Moron JC, Singer JA, Sardi A. Retrosternal goiter: A six-year institutional review. Am Surg 1998;64:889-93.

7. Grainger RG, Pierce JW. Mediastinal lesions. In: Sutton D, editor. A Textbook of Radiology and Imaging. Edinburgh:
Churchill Livingstone; 1980. p. 390-404.

8. Bashisht B, Ellis K, Gold RP. Computed tomography of intrathoracic goiters. AJR Am J Roentgenol 1983;140:455-60.

9. Barbetakis N, Chnaris A, Papoulidis P, Siobolas P, Kostopoulos G. Ectopic mediastinal thyroid gland. A case report and review of the literature. Hosp Chron 2010;5:99-102.

10. Grondin SC, Buenaventura P, Luketich JD. Thoracoscopic resection of an ectopic intrathoracic goiter. Ann Thorac Surg 2001;71:1697-8.

11. Kamby C, Andersen J, Ejlertsen B, Birkler NE, Rytter L, Zedeler K, et al. Pattern of spread and progression in relation to the characteristics of the primary tumour in human breast cancer. Acta Oncol 1991;30:301-8. 